a Programa de Pós-Graduação em Química, Departamento de Química, Universidade Federal de Mato Grosso, CEP 78060-900, Cuiabá-MT, Brasil.

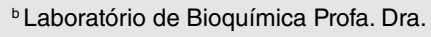
Nair Honda Kawashita, Departamento de Química, Universidade Federal de Mato Grosso, CEP 78060-900, Cuiabá-MT, Brasil.

' Programa de Pós-Graduação em Ciências da Saúde, Faculdade de Medicina, Universidade Federal de Mato Grosso, CEP 78060-900, Cuiabá-MT, Brasil.

\section{*E-mail: suelemfranca@ufmt.br}

Recebido em: 1 de março de 2021

Aceito em: 27 de agosto de 2021

Publicado em: 20 de Janeiro de 2022

\section{Análise da Composição Proximal, Marcadores Bioativos e Atividade Antioxidante Presentes no Mesocarpo de Acrocomia aculeata Colhidos no Estado de Mato Grosso}

\author{
Analysis of the Proximate Composition, Bioactive Markers and \\ Antioxidant Activity Present in the Mesocarp of Acrocomia aculeata \\ Fruit Harvested in the State of Mato Grosso
}

Francyele dos Santos Correia, ${ }^{a, b}$ Weliton B. da Silva, ${ }^{b}$ Fhelipe Jolner S. de Almeida, ${ }^{b, c}$ Kessya da Silva Bulhões, ${ }^{b}$ Suélem A. de França Lemes $a, b, c, *$ (i)

\begin{abstract}
This work aims to evaluate the proximate composition, phenolic compounds, flavonoids and antioxidant activity of the mesocarp (pulp) of the Acrocomia aculeata fruit (bocaiuva). The fruits were harvested (Poconé-MT) and the pulp used for proximal chemical determination using standard rules. Then, the pulp was lyophilized to obtain flour and used for the determination of total phenolics, flavonoids and antioxidant activity (DPPH). The bocaiuva presented $41 \%$ water, $33 \%$ carbohydrates, $18 \%$ lipids, $6 \%$ proteins, $2 \%$ ash, $50 \%$ total phenolics, $32 \%$ flavonoids and ability to reduce DPPH free radical to the lowest concentration, and at doses of 20 and $40 \mathrm{mg} / \mathrm{L}$, obtained the highest inhibitions. Therefore, bocaiuva pulp proved to be a source of lipids, carbohydrates, phenolic compounds, and flavonoids which were fundamental for the fruit to present a higher antioxidant capacity.
\end{abstract}

Keywords: Bocaiuva; total phenolic; DPPH

\section{Introdução}

A utilização de espécies vegetais ou produtos à base de plantas medicinais para o tratamento de diferentes patologias vem crescendo em todo o mundo nas últimas décadas, por se tratar de uma alternativa natural e de baixo custo, quando comparado aos medicamentos comercialmente disponíveis. ${ }^{1}$ Uma grande parcela da população acredita que, por ser um produto de origem natural, não há riscos à saúde e acabam consumindo elevadas concentrações dos preparados, seja na forma de chás, garrafadas ou xaropes. ${ }^{2}$

Embora diversas espécies medicinais sejam conhecidas e amplamente utilizadas, muitas ainda não possuem validação científica. Assim, continuam sendo de grande relevância os estudos relacionados à composição química dessas plantas, destacando os compostos bioativos, aspectos nutricionais e segurança no que se refere ao uso popular. ${ }^{3}$

A família Arecaceae, conhecida como família das palmeiras, possui cerca de 2.600 espécies vegetais, das quais 48 são nativas do território brasileiro, com ampla distribuição entre os biomas Caatinga, Cerrado e Amazônia. ${ }^{4}$ As espécies que compõem a família Arecaceae como a Cocos nucifera, Mauritia flexuosal L. f, Acrocomia aculeata (Jacq.) Lodd, são comumente utilizadas por comunidades tradicionais a exemplo dos povos indígenas, quilombolas e ribeirinhos que, através do conhecimento historicamente construído, fazem uso das mesmas como forma de subsistência, fonte de alimento e para o tratamento de processos inflamatórios e doenças como o diabetes. ${ }^{4-7}$

Acrocomia aculeata, conhecida popularmente como bocaiuva, macaúba, coco espinho, palmeira arara, dentre outros, é uma espécie vegetal que integra a família das palmeiras. Seu fruto é considerado um dos mais importantes do cerrado brasileiro, uma vez que são ricos em compostos bioativos de interesse terapêutico e apresentam elevado potencial para o desenvolvimento de novos produtos. ${ }^{8}$ A composição química dessa planta, os aspectos nutricionais e terapêuticos tornaram-se alvo de interesse industrial, devido à riqueza de fibras, minerais, compostos fenólicos e compostos bioativos lipofílicos, a exemplo dos carotenoides, ácidos graxos de cadeia média (constituídos de 6 a 12 átomos de carbonos), tocoferóis e vitamina A. ${ }^{4,9}$ 
O óleo extraído do mesocarpo da bocaiuva apresenta coloração alaranjada, evidenciando a presença de $\beta$-caroteno, que corresponde a aproximadamente $80 \%$ dos carotenoides totais. O interesse da indústria pela polpa se dá pela vasta possibilidade de processamento como: bolos, sorvetes, geleias e farinhas. Por outro lado, o conteúdo da polpa é rico em compostos bioativos com atividade antioxidante, podendo ser aplicado tanto para produtos alimentícios, quanto para fármacos ou cosméticos. ${ }^{10,11}$

Estudos demonstram a riqueza de ácidos graxos quantificados no mesocarpo da bocaiuva, sendo os três encontrados em maiores teores o ácido oleico (53,40-65,90\%), ácido palmítico (13,26-18,70\%) e o ácido linoleico $(8,75-17,70 \%)$. A castanha oleaginosa revestida pelo endocarpo é rica em ácido láurico $(38,89-58,60 \%)$, ácido oleico (12,80-25,50\%), ácido palmítico (4,70-17,35\%) e ácido mirístico $(8,00-11,00 \%){ }^{12}$

Tendo em vista a composição do fruto da bocaiuva encontrada na literatura, nosso grupo de pesquisa tem desenvolvido pesquisas relacionadas aos frutos regionais típicos do cerrado mato-grossense, tanto relacionados às propriedades químicas quanto nutricionais dos frutos. Neste sentido, o objetivo desse trabalho foi avaliar a composição do mesocarpo do fruto de Acrocomia aculeata, destacandose os macronutrientes, os compostos bioativos, e verificar sua atividade antioxidante.

\section{Materiais e Métodos}

\subsection{Reagentes}

Para o preparo das soluções de trabalho foram utilizados os seguintes reagentes: etanol PA (Dinâmica), metanol PA (NEON), ácido sulfúrico (Vetec), ácido clorídrico (Química Moderna), ácido bórico (Vetec), ácido acético glacial (ISOFAR), ácido gálico (Dinâmica), peróxido de hidrogênio (Próquimica), hidróxido de sódio (Dinâmica), carbonato de sódio (NEON), cloreto de alumínio (Dinâmica), rutina (Sigma), piridina (Synth), indicador misto verde de bromocresol (Mallinckrodt) e vermelho de metila (Nuclear), mistura catalítica (sulfato de cobre anidro (Synth), sulfato de potássio anidro (Vetec) e dióxido de titânio anidro (Dinâmica)), reagente Folin-Ciocalteu (Dinâmica), 2,2-difenil-1-picril-hidrazil (DPPH) (Sigma) e butil-hidroxitolueno (BHT) (Synth).

\subsection{Equipamentos}

Os equipamentos utilizados para o desenvolvimento deste trabalho foram: balança analítica com capela precisão de 0,0001 g Denver Instrument, liofilizador LS3000 Terroni, estufa com renovação e circulação de ar Nova ética, forno tipo mufla EDG 3000, espectrofotômetro UV-VIS 1240 Shimadzu, bloco digestor Gerhardt, destilador de nitrogênio Marconi 036 e aparelho extrator tipo Soxhlet.

\subsection{Coleta e armazenamento da polpa de bocaiuva} (Acrocomia aculeata)

A coleta dos frutos ocorreu no município de Poconé, localizado numa região de cerrado Mato-grossense $\left(16^{\circ}\right.$ 16'21.6”'S 56³7'34.5W, Poconé-MT). Os frutos maduros foram colhidos diretamente do pé e poucos encontrados caídos no solo. Em seguida, retiraram-se aqueles que estavam estragados e higienizaram-se os de boa qualidade deixando secar em local fresco à temperatura de $25^{\circ} \mathrm{C}$. Depois de secos, os frutos foram descascados manualmente e congelados para facilitar a retirada das polpas, que logo foram armazenadas em sacos plásticos devidamente identificados e submetidas à temperatura de $-20^{\circ} \mathrm{C}$. Para realizar o estudo, parte das polpas foram utilizadas para a determinação da sua composição proximal e outra parte para a produção da farinha de bocaiuva.

\subsection{Determinação da composição proximal e do valor energético da polpa de bocaiuva}

Os percentuais de umidade, cinzas, lipídeos totais e proteínas brutas da polpa da bocaiuva foram determinados seguindo os procedimentos do Manual de Normas do Instituto Adolf Lutz. ${ }^{13}$ Todas essas análises foram realizadas em triplicatas. $\mathrm{O}$ valor energético da polpa foi expresso em $\mathrm{KJ}$ (quilojoules) /grama da amostra e estimadas a partir dos fatores de conversão Atwater (1896): ${ }^{14}$ (17 KJ x g de proteínas $)+(17 \mathrm{KJ}$ x g de carboidratos $)+(37 \mathrm{KJ}$ x g de lipídeos).

\subsubsection{Determinação do teor de umidade e cinzas}

Para a determinação da umidade, cerca de $5 \mathrm{~g}$ de amostra foram pesadas em balança analítica com capela precisão de 0,0001 g (Denver Instrument) utilizando cápsulas de porcelanas, previamente aquecida em estufa (Nova ética) a $105^{\circ} \mathrm{C}$ e tarada. Após ser pesada, a amostra foi aquecida, também, a $105^{\circ} \mathrm{C}$ e após três horas de secagem, foi transferida e mantida em um dessecador com sílica gel em temperatura de $25^{\circ} \mathrm{C}$, sendo em seguida pesada. Repetiramse o procedimento de aquecimento e resfriamento até peso constante. $\mathrm{O}$ teor de umidade foi determinado segundo a Equação 1 e o resultado apresentado em \% de água/g da amostra.

$\%$ de água $=(100 \times$ perda de massa em gramas $) / \mathrm{g}$ da amostra

O teor de cinzas foi determinado utilizando-se o resíduo obtido na determinação da umidade. As amostras foram pesadas e, em seguida, incineradas em mufla (EDG 3000) a $550^{\circ} \mathrm{C}$ por aproximadamente 6 horas ou até apresentarem uma coloração esbranquiçada. Após a incineração, foram transferidas para um dessecador com sílica gel, onde ficaram até esfriar em temperatura de $25^{\circ} \mathrm{C}$. Pesaram-se as amostras e repetiram-se os procedimentos até peso constante. $\mathrm{O}$ 
percentual de cinzas foi determinado pela Equação 2 e os resultados expressos em \% de cinzas/g de amostra.

$\%$ de cinzas $=(100 \mathrm{x}$ g de cinzas $) / \mathrm{g}$ de amostra

\subsubsection{Determinação do teor de lipídeos totais}

Para a determinação de lipídeos totais, pesaram-se $3 \mathrm{~g}$ da amostra diretamente em cartuchos de papel filtro previamente tarado. Os cartuchos foram colocados em aparelho extrator tipo Soxhlet e $300 \mathrm{~mL}$ de solvente éter etílico P.A. foram adicionados no tubo de extração que, anteriormente, foi lavado e tarado. O solvente foi aquecido até ebulição, e permaneceu em refluxo e em contato com a amostra por aproximadamente 5 horas. Em seguida, o éter etílico foi destilado e o tubo de extração foi retirado e colocado em estufa a $105^{\circ} \mathrm{C}$ para evaporar resíduos do solvente, por aproximadamente 2 horas. $\mathrm{O}$ tubo foi transferido para um dessecador, onde permaneceu até resfriar. Depois de atingir a temperatura de $25^{\circ} \mathrm{C}$, o tubo foi pesado. A operação de aquecimento foi repetida em estufa por 30 minutos, até peso constante (por 2 horas no máximo). O teor dos lipídeos foi calculado segundo a Equação 3 e expressos em \% de lipídeos/g da amostra.

\% de lipídeos = (100 x g de lipídeos/g da amostra $)$

\subsubsection{Determinação do teor de proteínas brutas}

Pesaram-se $100 \mathrm{mg}$ das amostras secas e desengorduradas em um cartucho de papel de seda. As amostras foram transferidas para tubos de digestor de proteínas, onde foram adicionados $5 \mathrm{~mL}$ de ácido sulfúrico concentrado e $2 \mathrm{~g}$ de mistura catalítica. Os tubos foram colocados no digestor (Gerhardt), onde permaneceram por 3 horas a $340^{\circ} \mathrm{C}$. Após esse tempo, os tubos foram retirados do aquecimento e resfriados em temperatura de $25^{\circ} \mathrm{C}$. Após, $1 \mathrm{~mL}$ de peróxido de hidrogênio concentrado foi adicionado aos tubos. Os mesmos foram colocados novamente em aquecimento a $340^{\circ} \mathrm{C}$ até a solução adquirir uma coloração esverdeada e livre de material não digerível. Em seguida, a amostra foi destilada no destilador de nitrogênio (Marconi 036). Para isso, a amostra foi diluída com água destilada e, para deixála ligeiramente alcalina e neutralizar o excesso de ácido sulfúrico, foi acrescentado solução de hidróxido de sódio a $30 \%$. Ao destilado final, foram adicionados ácido bórico a $3 \%$ e indicador misto verde de bromocresol e vermelho de metila. A solução obtida foi titulada com ácido clorídrico a $0,1 \mathrm{M}$, até atingir uma coloração rosada. $\mathrm{O}$ teor de proteínas brutas foi determinado a partir da Equação 4 e os resultados foram expressos em \% de proteínas/g de amostra.

$\%$ de proteínas $=(\mathrm{V} \times 0,14 \times \mathrm{f} \times \mathrm{C}) / \mathrm{P}$

onde: V: volume gasto de ácido clorídrico na titulação; f: fator de conversão (utilizou-se 6,25); C: fator de correção da solução de ácido clorídrico após padronização; P: massa da amostra

\subsubsection{Determinação de carboidratos}

O conteúdo de carboidrato foi determinado por diferença do conteúdo de água, proteínas, lipídios e cinzas do peso inicial do mesocarpo fresco.$^{15}$

\subsection{Preparação da farinha de bocaiuva e determinação de compostos fenólicos e flavonoides totais}

Para o preparo da farinha de bocaiuva, a polpa foi liofilizada (liofilizador LS3000) por 6 dias consecutivos até peso constante e depois de seca, triturada com o auxílio de um gral e pistilo, até sua total moagem, obtendo-se assim a farinha de bocaiuva.

Para a determinação dos compostos fenólicos e flavonoides totais preparou-se um extrato etanólico da farinha de bocaiuva na proporção de 1:3 (amostra: etanol $70 \%) .{ }^{16}$ A mistura foi mantida sob o abrigo da luz, em contínua agitação magnética por 20 minutos em temperatura de $25^{\circ} \mathrm{C}$ e, em seguida, foi filtrada em funil de Büchner. $\mathrm{O}$ sobrenadante foi separado e o resíduo obtido foi submetido a mais duas extrações como descrito acima. Os sobrenadantes das três extrações foram unificados e utilizados para a determinação dos compostos bioativos citados.

\subsubsection{Determinação de compostos fenólicos totais}

A concentração de compostos fenólicos totais foi determinada segundo metodologia descrita por Amorim et al., 2008. ${ }^{17} \mathrm{Em}$ balões volumétricos de $10 \mathrm{~mL}$, sob o abrigo da luz, foram adicionados $5 \mathrm{~mL}$ de água destilada, $0,1 \mathrm{~mL}$ do extrato etanólico e $0,5 \mathrm{~mL}$ de solução aquosa do reagente Folin-Ciocalteu a 10\%. Após 3 minutos, foram adicionados $2 \mathrm{~mL}$ de solução aquosa de carbonato de sódio a $15 \%$ e o volume foi completado para $10 \mathrm{~mL}$ com água destilada. Após 90 minutos de repouso em temperatura ambiente, utilizando-se um espectrofotômetro UV-VIS 1240 Shimadzu, foi determinada a absorbância a $765 \mathrm{~nm}$. Uma curva de calibração foi construída com as concentrações de $0,5,1,0,2,0,2,5$ e $3,0 \mu \mathrm{g} / \mathrm{mL}$ de ácido gálico e utilizada para determinar a concentração de compostos fenólicos totais, que foi expressa em mg de fenólicos totais em equivalente de ácido gálico (EAG) por litro de extrato e por $100 \mathrm{~g}$ de farinha de bocaiuva (mg EAG/L ou mg EAG/100g).

\subsubsection{Determinação de flavonoides totais}

Para determinar a concentração de flavonoides totais, adicionaram-se em um balão volumétrico de $10 \mathrm{~mL}$, contendo previamente $5 \mathrm{~mL}$ de água destilada, uma alíquota de $1 \mathrm{~mL}$ do extrato etanólico, $60 \mu \mathrm{L}$ de ácido acético glacial a $99,5 \%, 1 \mathrm{~mL}$ de solução metanólica de piridina a $20 \%$ e $250 \mu \mathrm{L}$ de solução metanólica de cloreto de alumínio a 5\%. Completaram-se o volume para $10 \mathrm{~mL}$ com água destilada e a solução permaneceu em repouso por 30 minutos em temperatura de $25^{\circ} \mathrm{C}$. Passado o tempo, a absorbância foi determinada a $420 \mathrm{~nm}$ utilizando um espectrofotômetro UV-VIS 1240 Shimadzu. Construíram-se uma curva de calibração utilizando padrões de rutina nas concentrações de 3,0, 4,0, 8,0, 10,0, 12,0 
e $16,0 \mu \mathrm{g} / \mathrm{mL}$ para determinar a concentração dos flavonoides totais, que foi expressa em $\mathrm{mg}$ de flavonoides totais em equivalente de rutina (ERU) por litro de extrato e por $100 \mathrm{~g}$ de farinha de bocaiuva (mg ERU/L e mg ERU/100g). ${ }^{17}$

\subsection{Atividade antioxidante do extrato etanólico da farinha de Bocaiuva pelo sequestro do radical livre DPPH}

Para determinar a atividade antioxidante total do extrato etanólico da farinha da bocaiuva, fizeram-se quatro concentrações diferentes do extrato considerando a concentração de compostos fenólicos totais $(1,6,8,20$, $40 \mathrm{mg} / \mathrm{L}$ ). Em um tubo de ensaio, sob o abrigo da luz, adicionaram-se $100 \mu \mathrm{L}$ do extrato diluído e $3,9 \mathrm{~mL}$ de solução de 2,2-difenil-1-picril-hidrazil (DPPH, 0,06mM). Em seguida, mantiveram-se as amostras em repouso, protegidas da luz e em temperatura de $25^{\circ} \mathrm{C}$ por 45 minutos. Decorrido esse tempo, as leituras das amostras foram feitas utilizando um espectrofotômetro em $515 \mathrm{~nm}$. Utilizou-se álcool metílico como branco para zerar o espectrofotômetro. Uma solução de álcool etílico $70 \%$ foi utilizada como solução controle e o butil-hidroxitolueno (BHT) foi utilizado como padrão. Ambos foram submetidos às mesmas condições das amostras. A atividade antioxidante foi calculada em relação ao controle e expressa em percentual de sequestro do radical livre (\% SRL) segundo a Equação 5.

\% SRL $=\left(\frac{\text { Absorbância do Controle }- \text { Absorbância da Amostra }}{\text { Absorbância do Controle }}\right) \times 100$

A partir do cálculo da atividade antioxidante do extrato, em suas diferentes concentrações, a concentração necessária para reduzir 50\% do radical DPPH (Concentração de eficiência: $\mathrm{EC}_{50}$ ) foi calculada. Assim, uma curva linear entre a atividade antioxidante e sua concentração foi traçada, submetendo esses dados a uma regressão linear. Com isso, foi obtida uma equação da reta, a qual foi utilizada para determinar a $\mathrm{EC}_{50}$.

\subsection{Análise estatística}

As análises estatísticas foram realizadas utilizando o programa GraphPad Prism 9.0.0 para Windows (San Diego, Califórnia, USA). Testaram-se a normalidade dos dados pelo teste de Kolmogorov-Smirnov. Os resultados foram expressos como média \pm erro médio padrão (EMP) e as comparações foram feitas através do teste $t$ de Student. As diferenças encontradas foram consideradas estatisticamente significativas para um " $P$ " igual ou menor que 0,05 .

\section{Resultados}

\subsection{Composição proximal}

A composição proximal e o valor energético da polpa de bocaiuva estão apresentados na Tabela 1 .
Tabela 1. Composição proximal e o valor energético da polpa de bocaiuva

\begin{tabular}{lcc}
\hline \multirow{2}{*}{ Parâmetros } & \multicolumn{2}{c}{ Polpa de bocaiuva } \\
\cline { 2 - 3 } & $\begin{array}{c}\text { Composição } \\
\text { Percentual (\%) }\end{array}$ & $\begin{array}{c}\text { Valor Energético } \\
\text { KJ/100g }\end{array}$ \\
\hline Água & $41,23 \pm 0,18$ & - \\
Lipídeos & $18,01 \pm 1,59$ & 678,18 \\
Cinzas & $2,27 \pm 0,03$ & - \\
Proteínas Brutas & $5,78 \pm 1,09$ & 96,73 \\
Carboidratos & $32,68 \pm 2,67$ & 546,84 \\
Energia Total & $13,21 \mathrm{KJ} / \mathrm{g}$ de polpa & \\
\hline
\end{tabular}

Média \pm EMP das repetições em triplicata

\subsection{Compostos fenólicos totais, flavonoides totais e} atividade antioxidante da farinha de bocaiuva

Os resultados dos compostos fenólicos totais e flavonoides totais estão apresentados na Tabela 2. A concentração dos compostos fenólicos foi utilizada para determinar a atividade antioxidante total do extrato da farinha de bocaiuva através do cálculo do $\mathrm{EC}_{50}$. $\mathrm{O}$ extrato apresentou uma $\mathrm{EC}_{50} 29 \%$ menor que a $\mathrm{EC}_{50}$ do $\mathrm{BHT}$ (Tabela 2).

Tabela 2. Teores de compostos fenólicos totais, flavonoides totais e atividade antioxidante frente ao radical DPPH

\begin{tabular}{|c|c|c|}
\hline Amostra & & $\begin{array}{c}\text { Extrato Etanólico da Farinha } \\
\text { de Bocaiuva }\end{array}$ \\
\hline \multicolumn{3}{|c|}{ Compostos Fenólicos Totais } \\
\hline $\mathrm{mg}$ EAG/L & & $80,04 \pm 4,08$ \\
\hline mg EAG/100g & & $50,02 \pm 2,55$ \\
\hline \multicolumn{3}{|c|}{ Flavonoides Totais } \\
\hline mg ERU/L & & $51,72 \pm 3,42$ \\
\hline mg ERU/100g & & $32,31 \pm 2,14$ \\
\hline \multicolumn{3}{|c|}{ Atividade Antioxidante Total } \\
\hline & BHT & $\begin{array}{c}\begin{array}{c}\text { Extrato da Farinha de } \\
\text { Bocaiuva }\end{array} \\
\end{array}$ \\
\hline $\mathrm{EC}_{50}$ & $24,83 \mathrm{mg} / \mathrm{L}$ & $17,73 \mathrm{mg}$ EAG/L \\
\hline
\end{tabular}

A inibição percentual do radical DPPH foi determinada pelo extrato etanólico da farinha de bocaiuva e pelo antioxidante comercial BHT, usado como padrão, nas mesmas concentrações. Nas concentrações $1,6 \mathrm{mg} / \mathrm{L}$ e $8 \mathrm{mg} / \mathrm{L}$, a inibição do extrato e do BHT foi semelhante. Já o extrato, na concentração de 20 e $40 \mathrm{mg}$ EAG/L, apresentou maior inibição do radical DPPH de $14 \%$ e 19\%, respectivamente, quando comparado ao BHT (Figura 1).

\section{Discussão}

Dados reportados na literatura demonstram diferentes concentrações de constituintes químicos no fruto da Acrocomia aculeata. Aproximadamente $433 \mathrm{~g}$ de polpa de bocaiuva foram obtidas neste estudo a partir de 943,02 $\mathrm{g}$ da fruta descascada, das quais, após a etapa de liofilização 


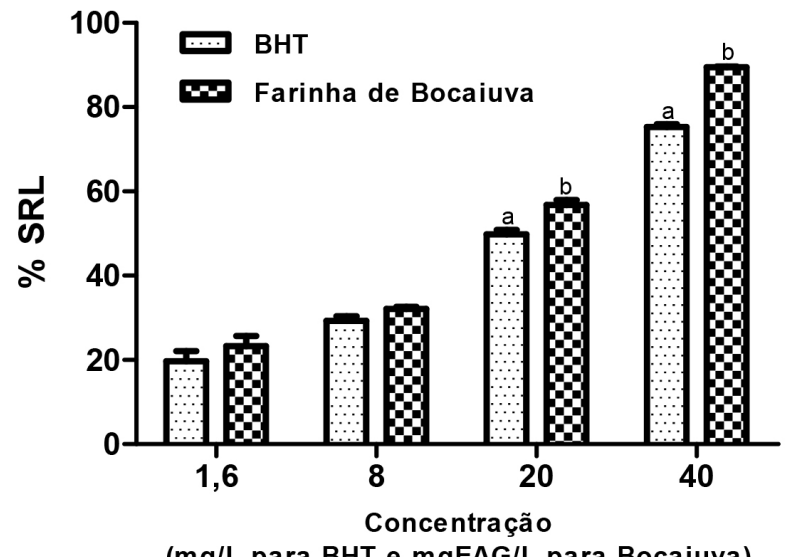

(mg/L para BHT e mgEAG/L para Bocaiuva)

Figura 1. Sequestro do radical livre (SRL) do DPPH (2,2-difenil-1picril-hidrazil), em porcentagem, pelo butil-hidroxitolueno (BHT) e farinha de Bocaiuva em diferentes concentrações. Os valores são expressos como as médias \pm erro médio padrão. Letras diferentes representam diferença estatística $(\mathrm{p}<0,05)$ teste $\mathrm{t}$ de Student. EAG (Equivalente de ácido gálico)

forneceram 257,17 $\mathrm{g}$ de peso final (rendimento de 59\%). Ao avaliar a composição química, a polpa de bocaiuva apresentou maiores teores de água (41\%) e carboidratos (33\%), seguidos de lipídeos (18\%), proteínas ( 6\%) e cinzas (2\%), totalizando $1321 \mathrm{KJ}$ de energia em $100 \mathrm{~g}$ de polpa. Os valores de umidade encontrados nos frutos coletados no Mato Grosso estão próximos aos valores encontrados por Lescano et al. (2015), ${ }^{18}$ coletados em Maracaju, Mato Grosso do Sul (MS), e superiores aos encontrados por Silva et al. (2019), ${ }^{8}$ coletados em Dourados, MS, e Andrade et al. (2020), ${ }^{11}$ coletados em Lavras, Minas Gerais (MG). Lescano et al. (2015) $)^{18}$ encontraram valores para carboidratos de 6,92\%, e 13,89\% para fibras. Já Andrade et al. $(2020)^{11}$ encontraram valores para carboidratos e fibras de $9,68 \%$ e $19,95 \%$, respectivamente, sendo $10,68 \%$ para fibras solúveis e $9,26 \%$ para fibras insolúveis. $\mathrm{O}$ valor encontrado neste estudo, relativo aos carboidratos, é referente aos carboidratos totais, incluindo as fibras. A polpa de bocaiuva contém elevados teores de lipídeos (18\%), o que está em acordo com outros estudos relacionados ao fruto. ${ }^{8,11,18,19}$ Esse elevado conteúdo de lipídeos encontrado na polpa de bocaiuva torna esse fruto atrativo para a obtenção de óleos. Os valores de proteínas brutas $(5,78 \%)$ são similares aos encontrados por Silva et al. (2019), ${ }^{8}(7,23 \%$ polpa in natura e $5,83 \%$ polpa desengordurada) e Lescano et al. (2015) $)^{18}$ (5,31\% polpa). Outros autores encontraram valores inferiores para proteínas encontradas na polpa, $0,6 \%{ }^{19} \mathrm{e} 2,87 \% .{ }^{11}$ Essas diferenças observadas entre os valores da composição proximal da polpa de bocaiuva de frutos da mesma espécie, porém, coletadas em diferentes regiões, pode ser explicada pela influência do solo, a fertilização, o clima e outros fatores ambientais fundamentais na maturação do fruto. ${ }^{20}$

Muitas plantas do Cerrado têm recebido uma especial atenção por serem fontes de compostos bioativos. ${ }^{21} \mathrm{Os}$ compostos fenólicos são muito comuns em plantas do
Cerrado como exemplos a carnaúba (Copernicia prunifera (Mill.) H.E. Moore), murici (Byrsonima crassifolia L. Rich), oiti (Licania tomentosa (Benth.) Fritsch), ${ }^{22}$ guapeva (Pouteria cf. Guardneriana Radlk) e o tucumã (Astrocaryum aculeatum $),{ }^{23}$ isso provavelmente é devido a uma proteção da planta em função da exposição ao estresse hídrico, alta radiação ultravioleta, ataques de herbívoros e infecções fúngicas. ${ }^{24} \mathrm{~A}$ farinha da polpa de bocaiuva avaliada no estudo apresentou teores de compostos fenólicos de 50,02 $\pm 2,55 \mathrm{mg}$ EAG/100g e teores de flavonoides de 32,31 mg ERU/100g. Os valores encontrados nesse trabalho para compostos fenólicos totais estão próximos aos encontrados por Siqueira (2012) quando utilizou extrato etanólico da polpa fresca da bocaiuva para avaliar compostos fenólicos totais $(44 \pm 1 \mathrm{mg}$ EAG/100g). ${ }^{25}$ Valores de compostos fenólicos totais obtidos a partir de extratos alcoólicos de bocaiuva em estudo feito por Rocha et al. (2013) foram superiores aos encontrados nesse estudo $\left(60,85 \mathrm{mg}\right.$ EAG/100g do fruto). ${ }^{19}$ A quantidade de fenólicos totais em um fruto pode ser influenciada pelo método de extração (melhores resultados usando metanol), variedade do fruto, região e estágio de maturação. ${ }^{25}$ Embora os teores de flavonoides encontrados nesse trabalho, sejam próximos aos valores encontrados por Siqueira (2012) (35 \pm $3 \mathrm{mg} \mathrm{CE} / 100 \mathrm{~g}),{ }^{25}$ a comparação é limitada em função do padrão utilizado nos experimentos. Nesse trabalho, foi utilizada a rutina como padrão, ${ }^{26,27}$ enquanto Siqueira (2012) utilizou catequina. ${ }^{28}$ É importante destacar que a concentração de compostos com atividade antioxidante encontrados na literatura é maior na polpa que no óleo da amêndoa de bocaiuva. Além disso, embora não tenha sido avaliado no presente estudo, a polpa também é rica em carotenoides o que a torna importante fonte de antioxidantes como a vitamina A. ${ }^{29,30}$

Os resultados obtidos para atividade antioxidante total do extrato etanólico da farinha da polpa de bocaiuva, expressos na capacidade de reduzir em 50\% o radical DPPH $\left(\mathrm{EC}_{50} \mathrm{mg} / \mathrm{L}\right)$, apontaram elevado poder antioxidante para a farinha de bocaiuva. A farinha avaliada nesse estudo apresentou capacidade de redução em 50\% do radical livre DPPH com a menor concentração quando comparada ao antioxidante BHT, sendo que, nas doses de 20 e $40 \mathrm{mg} / \mathrm{L}$, conduziram a maiores inibições quando comparados ao BHT. Outro trabalho avaliando a atividade antioxidante de extratos alcoólico $\left(\mathrm{EC}_{50} 3582,54 \mathrm{mg} / \mathrm{L}\right)$ e aquoso $\left(\mathrm{EC}_{50}\right.$ $3783,81 \mathrm{mg} / \mathrm{L}$ ) da A. aculeata reporta valores superiores de $\mathrm{EC}_{50}$ aos encontrados nesse estudo. ${ }^{19}$ Andrade et al. (2020) relataram valores para $\mathrm{EC}_{50}$ de $290,86 \mathrm{~g}$ de fruto/ $\mathrm{g}$ de DPPH para a polpa de A. aculeata colhida em Minas Gerais (MG) ${ }^{11}$ Esses resultados comparados aos obtidos nesse estudo mostram o elevado potencial antioxidante da polpa de Bocaiuva, os quais, associados à composição nutricional da polpa, configuram-na como matéria-prima relevante para novas aplicações industriais, os quais poderiam enriquecer alimentos e bebidas. Entretanto, ressalta-se a necessidade de maiores estudos para avaliar a viabilidade dos alimentos processados com esse fruto. 


\section{Conclusão}

A polpa de bocaiuva possui elevados teores de lipídeos, carboidratos, água e menor teor de proteínas. A farinha da polpa de bocaiuva demonstrou possuir elevada concentração de compostos fenólicos e flavonoides, comparados aos outros estudos contendo extratos etanólicos. Esses resultados da polpa e da farinha de bocaiuva justificam sua atividade frente ao radical DPPH.

Considerando que a Acrocomia aculeata é uma palmeira amplamente distribuída na região, o uso da farinha de bocaiuva torna-se interessante por ser de baixo custo e alto valor nutritivo. Além disso, a exploração de produtos florestais, não madeireiros geram emprego e renda para a população de maior vulnerabilidade social. A partir dos resultados obtidos, este estudo sugere a possibilidade do uso deste fruto como suplemento alimentar alternativo em estudos que avaliam os efeitos antioxidantes in vivo.

\section{Agradecimentos}

O presente trabalho foi realizado com apoio da Coordenação de Aperfeiçoamento de Pessoal de Nível Superior - Brasil (CAPES) - Código de Financiamento 001. Os autores agradecem também à Universidade Federal de Mato Grosso (UFMT) pela infraestrutura disponível. Este trabalho é parte da dissertação apresentada por Francyele dos Santos Correia como requisito parcial para a obtenção do grau de mestre do Programa de Pós-graduação em Química da UFMT.

\section{Referências Bibliográficas}

1. Wang, Y. Y., Lin, S. Y., Chen, W. Y., Liao, S. L., Wu, C. C., Pan, P. H., Chou, S. T., Chen, C. J.; Glechoma hederacea extracts attenuate cholestatic liver injury in a bile duct-ligated rat model. Jornal of Ethnopharmacol 2017, 204, 66._CrossRef] [PubMed]

2. Zeni, A. L. B.; Parisotto, A. V.; Mattos, G.; Helena; E. T. S.; Utilização de plantas medicinais como remédio caseiro na Atenção Primária em Blumenau, Santa Catarina, Brasil. Ciência e Saúde Coletiva 2017, 22, 2712. [CrossRef][PubMed]

3. Ekor, M.; The growing use of herbal medicines: issues relating to adverse reactions and challenges in monitoring safety. Frontiers Pharmacology 2013, 4, 177. [CrossRef] [PubMed]

4. Souza, F. G., De Araújo, F. F., Farias, D. P., Zanotto, A. W., Neri-Numa, I. A., Pastore, G. M.; Brazilian fruits of Arecaceae family: An overview of some representatives with promising food, therapeutic and industrial applications. Food Research International 2020, 138. [CrossRef] [PubMed]

5. Silva, P. V. B.; Ramiro, M. M.; Iriguchi, E. K. K.; Corrêa, W. A.; Lowe, J.; Cardoso, C. A. L.; Arena, A. C.; Kassuya, C. A. L.; Muzzi, R. M.; Antidiabetic, cytotoxic and antioxidant activities of oil extracted from Acrocomia aculeata pulp. Natural Product Research 2019, 33, 2416. [CrossRef] [PubMed]

6. Borges, R. M.; Moreira, R. P. M.; Estudo etnobotânico de plantas medicinais no município de Confresa Mato Grosso, Brasil. Biodiversidade 2016, 3, 15. [Link]

7. Bortoluzzi, R. N.; Moreira, L. L.; Vieira, C. R.; Diversidade de plantas alimentares em quintais agroflorestais de Cuiabá e Várzea Grande, Mato Grosso, Brasil. Interações 2021, 22, 307. [CrossRef]

8. Silva, A. O.; Cortez-Vega, W. R.; Prentice, C.; Fonseca, G. G. Development and characterization of biopolymer films based on bocaiúva (Acromoni aculeata) fluor. International Journal of Biological Macromolecules 2019, 155, 1168. [CrossRef] [PubMed]

9. Silva, C. A. A.; Fonseca, G. G.; Brazilian savannah fruits: Characteristics, properties, and potential applications. Food Science and Biotechnology 2016, 25, 1232. [CrossRef] [PubMed]

10. Silva, R. C., Batista, A., da Costa, D. C. F., Moura-Nunes, N., Koury, J. C., da Costa, C. A., Resende, A. C., Daleprane, J. B.; Açaí (Euterpe oleracea Mart.) seed flour prevents obesityinduced hepatic steatosis regulating lipid metabolism by increasing cholesterol excretion in high-fat diet-fed mice. Food Research International 2018, 111, 415. [CrossRef] [PubMed]

11. Andrade, C. A.; Marinho, J. F. U.; Souza, A. C.; Tavares, T. S.; Dias, D. R.; Schwan, R. F.; Nunes, C. A.; Bastos, S. C.; Prebiotic potential of pulp and kernel cake from Jerivá (Syagrus romanzoffiana) and Macaúba palm fruits (Acrocomia aculeata). Food Research International 2020, 136, 26. [CrossRef] [PubMed]

12. Mota, C. S., Corrêa, T .R. C., Grossi, J. A. S., Ribeiro, A. S Sustainable exploitation of macauba for biodiesel production: Harvest, post-harvest and fruit quality. Informe Agropecuario 2011, 32, 51. [Link]

13. Zenebon, O.; Pascuet, N. S., eds; Métodos físico-químicos para análise de alimentos, $4^{\mathrm{a}}$ ed. ( $1^{\mathrm{a}}$ Edição digital), Instituto Adolfo Lutz: São Paulo, 2008.

14. Atware, W. O.; Woods, C. D.; The chemical composition of American food materials. Disponível em: < https://www.ars. usda.gov/ARSUserFiles/80400525/Data/Classics/es028.pdf>. Acesso em: 1 março 2021.

15. Helrich, K.; Official Methods of Analytical chemistry. Association of Official Analytical Chemists, $15^{\mathrm{a}}$ ed., Arlington, VA: Virgínia, 1990.

16. Aragão, T.F.; Trabalho de Conclusão de Curso, Universidade Tecnológica Federal do Paraná, 2014. [Link]

17. Amorim, E. L. C; Nascimento, J. E.; Monteiro, J. M.; Sobrinho, T. J. S. P.; Araújo, T. A. S.; Albuquerque, U. P.; A simple and Accurate Procedure for the Determination of Tannin and Flavonoid Levels and Some Applications in Ethnobotany and Ethnopharmacology. Global Science Books, Special Issue 2008 , 1, 88. [Link]

18. Lescano, C. H.; Iwamoto, R. D.; Sanjinez-Argandoña, E. J.; Kassuya, C. A. L.; Diuretic and anti-inflammatory activities of the microencapsulated Acrocomia aculeata (Arecaceae) oil on Wistar rats. Journal of medicinal food 2015, 18, 662. [CrossRef] [PubMed] 
19. Rocha, M. S.; Figueiredo, R. W.; Araújo, M. A. M.; MoreiraAraújo, R. S. R.; Caracterização físico-química e atividade antioxidante (in vitro) de frutos do cerrado piauiense. Revista Brasileira de Fruticultura 2013, 35, 94. [CrossRef]

20. Pimentel, T.; Pizzuti, L.; Fakhouri, F. M.; Innocentini-Mei, L .H.; Fonseca, G. G., Development of multilayer films obtained from epoxidized methyl esters, polyhydroxyalkanoates and their combinations. Journal of Polymers and the Environment 2018, 26, 1672. [CrosssRef]

21 Vieira, R. F.; Costa, T. S. A.; Silva, D. B.; Ferreira, F. R.; Sano, S. M., Frutas Nativas da Região Centro-Oste do Brasil. Embrapa Recursos Genéticos e Biotecnologia 2006 [Link]

22. Moreira-Araújo, R. S. R. ; Barros, N. V. A.; Porto, R. G. C. L.; Brandão, A. C. A. S.; Lima, A.; Fett, R.; Bioactive compounds and antioxidant activity three fruit species from the Brazilian Cerrado. Revista Brasileira de Fruticultura 2019, 3, 41. [CrossRef]

23. Soares, C. M. S; Morais, R. A.; Santos, A. L. S.; Souza, H. M. S.; Teles, J. S.; Silva, R. R.; Souza, A. R. M.; Martins, G. A. S.; Quantificação de compostos fenólicos totais em frutos não convencionais cultivados no cerrado. Revista Desafios 2020, 7, $71[$ CrossRef]
24. Fank-de-Carvalho, S. M.; Somavilla, N. S.; Marchioretto, M.S.; Báo, S. N.; Em Plant structure in the Brazilian neotropical savannah species. Lo Y.H.; Blanco, J. A.; Roy, S., eds; IntechOpen: New York, $1^{\mathrm{a}}$ ed., 2015, cap. 16.

25. Siqueira, P.B.; Tese de Doutorado. Universidade estadual de Campinas, 2012. [Link]

26. Ma, X.; Wu, H.; Liu, L.; YaO, Q.; Wang, S.; Zhan, R.; Xing, S.; Zhou, Y.; Polyphenolic compounds and antioxidant properties in mango fruits. Scientia Horticulturae 2011, 129, 107. [CrossRef]

27. Zhishen, J.; Mengcheng, T.; Jianming, W.; The determination of flavonoid contents in mulberry and their scavenging effects on superoxide radicals. Food Chemistry 1999, 64, 559. [CrossRef]

28. Chun, O. K.; Kim, D.; Smith, N.; Schroeder, D.; Han, J. T.; Lee, C. Y.; Daily consumption of phenolics and total antioxidant capacity from fruit and vegetables in the American diet. Journal of Science and Food Agricultural 2005, 85, 1724. [CrossRef]

29. Kartha, V. N.; Krishnamurthy S.; Antioxidant function of vitamin A. International Journal of Vitamin and Nutrition Research 1977, 47, 401. [PubMed]

30. Ramos, M. I. L.; Siqueira, E. M.; Isomura, C. C.; Barbosa, A. M.; Arruda, S. F.; Bocaiuva (Acrocomia aculeata (Jacq.) Lodd) improved vitamin A status in rats. Journal of agricultural and foodchemistry 2007, 55, 3190. [CrossRef] [PubMed] 